\title{
Gênero, discriminação e diversidade sexual em perspectiva política, no México (2012-2018)
}

Resumo: No ano de 2016, Enrique Peña Nieto (2012-2018), presidente do México, enviou ao Congresso um projeto de lei referente à aprovação do casamento entre pessoas do mesmo sexo. Analisando documentos oficiais da sua candidatura, partido e presidência, como o Programa de Ação, Declaração de Princípios das Convocatórias do PRI (Partido Revolucionário Institucional) e Plano Nacional de Desenvolvimento, não foram encontradas referências diretas à questão da "preferência sexual", tal qual aparece na Constituição, que demonstrassem linhas de ação direcionadas às pessoas LGBTQIA+. A "perspectiva de gênero", diretriz manifesta nesses documentos, referir-se-á unicamente à demanda das mulheres e condição social das mexicanas, sendo que já se constituíam em leis e políticas públicas desde o início do século XXI. Considerando a distância entre as propostas dos documentos oficiais e as iniciativas políticas de Peña Nieto, no tocante aos indivíduos com outras formas de vivência da sexualidade, este artigo discute a atuação presidencial como estratégia política e de autopromoção, uma vez que se encontrava em meio a uma grande crise de popularidade e denúncias de corrupção.

Palavras-chave: México, Enrique Peña Nieto, Perspectiva de Gênero

\section{Gender, discrimination, and sexual diversity from a political perspective in Mexico (2012-2018)}

\begin{abstract}
In 2016, Enrique Peña Nieto (2012-2018), President of Mexico, sujected a bill to congress on the approval of same-sex marriage. Analyzing official documents of his candidacy, party, and presidency, such as the Action Program, Declaration of Principles of the PRI (Institutional Revolutionary Party), and National Development Plan, no direct references to the issue of "sexual preference" were found, such as appears in the constitution including lines of action aimed at LGBTQIA+QIA+ people. The "gender perspective", a guideline expressed in these documents, refers only to the demand of women and the social status of Mexican women, since they were already constituted in laws and public policies since the beginning of the 21 st century. Considering the distance between the proposals in official documents and Peña Nieto's

\footnotetext{
${ }^{1}$ Doutora em História e professora de História das Américas na Universidade Estadual de Londrina (UEL). E-mail: edmeialondrina@uel.br
} 
political initiatives regarding individuals with other forms of experiencing sexuality, this article discusses presidential actions as a political and self-promotion strategy, since it emerged during a major crisis of popularity and accusations of corruption.

Keywords: Mexico, Enrique Peña Nieto, Gender Perspective

Artigo recebido em: 09/07/2021

Artigo aprovado para publicação em: 30/11/2021

No México, a questão religiosa figura como um emblema do país, seja na sua forma primeira de manifestação (crença, fé, devoção) ou simbolizada pela recusa da sua presença - enquanto instituição - no local de atuação do Estado (anticlericalismo). É o que pode ser percebido nas reflexões de Brian Hamnett (2016), as quais mostram que a insurreição de 1810, cuja característica foi uma grande participação popular sob a liderança de um padre - Miguel Hidalgo -, culminou na independência daquele espaço. É ali também onde se encontra (até a atualidade) grande número de devotos da Virgem de Guadalupe, expressão do conjunto das tradições, hábitos sociais e religiosos mexicanos. "A dimensão religiosa enraizou-se profundamente na cultura popular da Nova Espanha”, diz Hamnett, tanto que a hierarquia católica tentou definir a identidade nacional mexicana a partir do catolicismo (2016. p. 157-255).

Entre 1916 e 1937, em diferentes momentos, aconteceram intensos conflitos entre a população católica e as autoridades representantes da Revolução Mexicana. Os conflitos se deram em decorrência dos artigos anticlericais da Constituição de 1917, que regulamentavam a presença e atuação da Igreja na educação e na sociedade. A Presidência de Plutarco Elias Calles (1924-1928) foi a mais rigorosa no tocante à observação aos preceitos da Constituição, disciplinando a sua plena aplicação no ano de 1926, o que levou a diversas rebeliões, sendo que a maior e mais duradoura foi a Rebelião Cristera, de 1926 até 1929 (PÉREZ RAYÓN, 2008, p. 161-202).

O restabelecimento das relações mais próximas entre Estado e Igreja acontecerá somente na década de 90. Para Soledad Loaeza (2013), em 1991 Carlos Salinas de 
Gortari (1988-1994) anunciou que faria revisão da legislação referente à Igreja, vigente desde a Constituição promulgada em 1917. O presidente do México argumentou sobre a necessidade de transformar uma lei que fora criada em um período de conflitos já superados$^{2}$. Desta forma, conforme destaca Brian Hamnett, em 1993 o governo de Salinas retomou os vínculos com o Vaticano, desfeitos desde a época em que Benito Juárez (1858-1872) fora presidente, em 1867. Na década de 1990, o México vivenciou uma experiência católica mais forte, com tendências fundamentalistas - tentativas de tirar o nome de Juárez das ruas, propostas para colocar advertência nos pacotes de preservativos (igual às dos cigarros), críticas à educação secular -, ideias que se ancoravam na falta de observação dos preceitos morais do catolicismo. $\mathrm{O}$ autor prossegue destacando que,

O cardeal Rivera foi acusado de intolerância, pois culpava os homossexuais, as feministas e outras 'minorias' pelos males do México contemporâneo. A Crítica episcopal do modelo neoliberal, alegando que ele exacerbava as carências sociais, somou-se aos ataques à conduta sexual liberal para dar a impressão de que a igreja oficial estava envolvida, ao mesmo tempo, em uma crítica concertada ao liberalismo da esquerda e da direita (HAMNETT, 2016, p. 310-311).

Para ele, a Igreja Católica procurou exercer um controle maior sobre o Estado e a sociedade. As aspirações clericais caminhavam no sentido de controle rigoroso do comportamento público (HAMNETT, 2016, p. 311).

No México, a relação entre Igreja e Estado também se constitui em tema para Soledad Loaeza, que busca entender, em sua obra La restauración de la iglesia católica en la transición mexicana, a presença e retomada de forças desta instituição no país. Nas reflexões que nos apresenta, destaca a presença física e constante do Vaticano no

\footnotetext{
${ }^{2}$ A mudança no status jurídico da igreja católica no México também está vinculada a uma política do Vaticano em relação à América Latina com o objetivo de restaurar a hegemonia católica no continente e recuperar a autoridade papal não só sobre a população, mas também sobre os religiosos (LOAEZA, 2013, p.155).
} 
México $^{3}$. Para ela, o México configurou-se como um espaço importante na ação de restauração da Igreja Católica na América Latina. Apesar da política de secularização, a Igreja Católica continuou como uma instituição sólida, mesmo com a legislação anticlerical e bastante obediente ao Papa (LOAEZA, 2013, p. 170).

Esta mesma autora mostra que, em 2010, a hierarquia católica no México, cumprindo instruções vindas do Vaticano, decidia dar um basta em práticas e comportamentos provenientes da sociedade moderna. A investidura que ordenava defender o direito à vida e a família tradicional - rechaçando a questão do aborto e do casamento entre pessoas do mesmo sexo -, não foi seguida somente pela Igreja; contou com o apoio do governo federal, do PAN (Partido da Ação Nacional) e do PRI (Partido Revolucionário Institucional). Para ela, no governo de Miguel de la Madrid (1982-1988) iniciou-se uma participação política mais ativa, por parte da Igreja (LOAEZA, 2013, p. 173). Neste mesmo sentido, Hamnett lembra que em 2000, com a vitória de Vicente Fox (2000-2006) do PAN, a Igreja mexicana continuou insistindo para que pudesse ministrar a disciplina de Educação Religiosa nas escolas primárias estaduais, criticando a secularização da educação, denunciando as "práticas sexuais liberais", entre outras frentes de natureza moral (HAMNETT, 2016, p. 337). Na atualidade, vivencia-se uma onda conservadora, com discursos em favor da moralidade e contra as conquistas das mulheres e pessoas LGBTQIA+.

\section{Sobre o entendimento do conceito gênero no México}

Conforme o campo de estudos de gênero - tributários da História das Mulheres - tem se pronunciado, não só nas academias, mas em organizações e instituições orientadas ao trabalho e debate sobre a condição social das mulheres e a diversidade sexual, nota-se, inclusive no México, o despontar de um discurso contrário ao gênero, pautado na moral sexual e familiar conservadora. No atual momento, podemos

\footnotetext{
${ }^{3}$ João Paulo II fez cinco visitas ao México: em 1979, 1990, 1993, 1999 e 2002. Bento XVI foi em 2012 e o Papa Francisco em 2016.
} 
acompanhar em vários países os debates e as disputas políticas que caracterizam uma ofensiva sobre questões de gênero. Protestos e resistências têm aparecido com intensidade e força política protagonizados por instituições religiosas e movimentos conservadores criticando e disseminando discordâncias que acirram inúmeras polêmicas acerca dessa discussão. Percebe-se um discurso alarmista que tem tomado considerável dimensão em programas e projetos políticos, na mídia impressa e digital, nas redes sociais, em organizações, movimentos coletivos, igrejas etc., e tocado vigorosamente os imaginários sociais. Trata-se do discurso antigênero, mais comumente conhecido, como define Rogério Diniz Junqueira, pela estrutura discursiva "teoria/ideologia de gênero" e constitui-se em uma "ofensiva religiosa reacionária transnacional" para reafirmar valores tradicionais, difundindo movimentos de cunho social e político pautados pelo modelo cristão, cujo cerne consiste na defesa da vida e da família heterossexual (JUNQUEIRA, 2016, p. 229).

$\mathrm{Na}$ contramão da força e potencialidade do discurso antigênero, e até mesmo contrariando o próprio partido, em 17 de maio de 2016, o presidente do México, Enrique Peña Nieto (2012-2018), enviou ao Congresso, com o apoio do Supremo Tribunal de Justiça, um projeto de lei propondo a aprovação do casamento civil entre pessoas do mesmo sexo ${ }^{4}$. O envio desse projeto ao Congresso provocou uma onda conservadora/reacionária no México e fez com que no dia seguinte (18 de maio de 2016) surgisse a Frente Nacional por la Familia, composta por diversas organizações, de cunho religioso e laicos também ${ }^{5}$.

\footnotetext{
${ }^{4}$ De acordo com reportagem no Jornal El País, o próprio partido de Peña Nieto não encampou o envio do projeto à câmara. "O PRI congelou a iniciativa presidencial no Congresso". O cenário de impopularidade da proposta do casamento entre pessoas do mesmo sexo nos estados mais conservadores e derrotas nas eleições regionais e desgaste do próprio presidente levou os parlamentares a virarem as costas ao projeto de união homoafetiva, por já estarem considerando uma recuperação para as próximas eleições presidenciais.

Disponível

em:

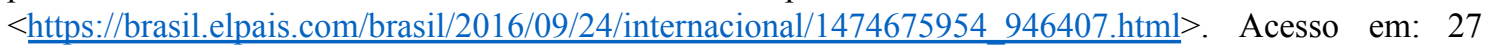
nov. 2017.

${ }^{5}$ A Frente Nacional por la Familia é liderada, no México, pela Confamília - Consejo Mexicano de la Familia (associação que não está vinculada a nenhuma religião ou partido); a UNPF - Unión Nacional de Padres de Familia (existe desde 1917); Red Familia (surgiu em 1999 e é formada por 5 instituições Associación Gilberto AC, Alianza latino-americana para la família - ALAFA, ENLACE, Familia y Sociedad AC, Unión Nacional de padres de família AC).
} 
Essa mobilização da Igreja e de movimentos pela família, ou seja, essa ampla frente, em conjunto com uma ofensiva eclesiástica, católica, liderada pelo Cardeal Norberto Rivera $^{6}$, conseguiu que a Comissão de Assuntos Constitucionais rejeitasse, na Câmara dos Deputados, em 9 de novembro de 2016, que a aprovação da conjugalidade entre homossexuais fosse discutida no Congresso ${ }^{7}$.

Ao procurar entender as motivações políticas do Presidente Enrique Peña Nieto para ter tomada tal iniciativa, ${ }^{8}$ uma vez que em seu Plano Nacional de Desenvolvimento (PND 2013/2018) não foi encontrado nenhum item abordando textualmente a demanda da população LGBTQIA+, deparamo-nos com as questões de gênero. Nele, o governo ressalta ser o primeiro PND a incorporar a perspectiva de gênero como princípio essencial:

Este és el primer Plan Nacional de Desarollo que incorpora una perspectiva de género como principio esencial. És decir, que contempla la necesidad de realizar acciones especiales orientadas a garantizar los derechos de las mujeres y evitar que las diferencias de género sean causa de desigualdade, exclusión o discriminación (PLAN NACIONAL DE DESARROLLO, 2013-2018, p. 23).

\footnotetext{
${ }^{6}$ Arcebispo complacente com padres pedófilos e muito envolvido também com as elites. Sua figura ficou marcada por defender o pedófilo Marcial Maciel, fundador dos Legionários de Cristo. Perdeu o crédito, sua figura pública ficou prejudicada, mas nunca perdeu a influência. Na atualidade, em função da cruzada contra a "ideologia de gênero", o setor mais extremista do episcopado o trouxe de volta à atuação pública. El País. Igreja mexicana tira a ultradireita das catacumbas em ofensivas antigays. 24 set. 2016. Disponível em: <https://brasil.elpais.com/brasil/2016/09/24/internacional/1474675954 946407.htmll>. Acesso em 01 nov. 2018.

${ }^{7}$ De acordo com Gloria Careaga-Perez, embora o Congresso não tivesse discutido a proposta de Peña Nieto, a Suprema Corte já havia declarado que todas as leis locais que impedissem o casamento igualitário seriam inconstitucionais e deveriam ser cumpridas. Em seu entendimento, o Presidente procurou formalizar essa resolução do Tribunal de Justiça, mas o casamento poderia/pode ser feito em qualquer estado, mesmo sem a existência da lei pois, em caso de negativa do cartório, podem - e devem, em suas palavras - recorrer ao Tribunal, o qual obrigará o Estado a proceder a união. (As concepções de Gloria Careaga-Perez aqui explicitadas, fazem parte de uma entrevista/consulta, realizada por e-mail em julho de 2018.)

${ }^{8}$ Além dos documentos oficiais do governo e do partido de Enrique Peña Nieto (Plan Nacional de Desarrollo - 2013-2018; Declaração de Princípios de Assembleias Nacional do PRI - 2013 e 2017; Programa de Acción, PRI 2013 e 2017), Constitución Política de los Estados Unidos Mexicanos, 2014, o corpus documental que deu suporte às análises presentes neste artigo também compreende sites institucionais de diversas vertentes ideológicas da imprensa mexicana e o site do governo mexicano - no qual encontram-se disponíveis, para consulta, programas, projetos, leis, ações voltados a erradicar a violência contra as mulheres e outras iniciativas relativas à "equidade de gênero".
} 
O plano foi estruturado em objetivos das políticas públicas, ações para atingi-las e indicadores para medir os avanços. Foram delineadas três estratégias transversais, sendo a Perspectiva de Género uma delas, projetando sua aplicabilidade na totalidade das políticas e ações dessa administração (PLAN NACIONAL DE DESARROLLO, 2013-2018, p. 9-10) ${ }^{9}$. Justifica-se, no documento, que o objetivo foi alcançar a igualdade substancial, de fato, entre homens e mulheres, para garantir seus direitos e evitar as diferenças. Nota-se, dessa forma, que todas as linhas de ação trazem a demanda da mulher: erradicação da violência, discriminação, diferenças, homicídios, igualdade, oportunidades iguais, direitos, entre outros. Ao final do Plano Nacional de Desenvolvimento, o Índice de Desigualdade de gênero destaca três dimensões das desvantagens que sujeitam as mulheres, quais sejam, saúde reprodutiva, empoderamento e mercado de trabalho (PLAN NACIONAL DE DESARROLLO, 2013-2018, p. 162) ${ }^{10}$.

Entre os programas sistematizados para serem elaborados na administração de Peña Nieto, estão o programa para prevenir, atender, sancionar e erradicar a violência contra as mulheres, além de um outro com o propósito de prevenir e eliminar a discriminação. Este documento não traz referência textual literal a hostilidades relativas à preferência sexual, embora estabeleça políticas para a discriminação. A expressão "perspectiva de gênero", neste documento, evidencia que a concepção se refere, notadamente, à condição social das mulheres. Neste mesmo sentido, chama-nos a atenção que os itens e ações que abordam a questão da discriminação não especificam se essa "discriminação de pessoas ou grupos" refere-se às pessoas homossexuais, bissexuais, transexuais. Entre os programas do Sistema Nacional de Planeación Democrática, além do Programa Nacional para la Igualdad de Oportunidades y no

\footnotetext{
${ }^{9}$ Os objetivos são: México en paz; México Incluyente; México con Educación de Calidad; México Próspero; México con Responsabilidad global. As estratégias transversais são: Democratizar la Productividad; Gobierno Cercano y Moderno e Perspectiva de Género.

${ }^{10}$ São destacados cinco indicadores que medem tais dimensões: 1) Taxa de mortalidade materna; 2) Taxa de fecundidade de adolescentes; 3) Mulheres e homens com pelo menos a educação secundária completa, 4) Participação de mulheres e homens em assentos parlamentares e 5) Taxa de participação de mulheres e homens no mercado de trabalho.
} 
Discriminación contra las Mujeres e o Programa Integral para Prevenir, Atender, Sancionar e Erradicar la Violencia contra las Mujeres, encontramos também o Programa Nacional para Prevenir y Eliminar la Discriminación; contudo não é possível identificar, especificamente, a qual discriminação o documento se refere. Dessa forma, no Plano de Governo de Peña Nieto, três questões ficaram perceptíveis. A primeira é a ênfase, a visibilidade e os planejamentos voltados às mulheres; que a referência a gênero diz respeito somente a elas e, por último, que a expressão/ideia/concepção de diversidade sexual ou preferência sexual não aparecem, explicitamente, no texto do documento.

Nas buscas realizadas pela internet não foi possível encontrar documento oficial que explicitasse as motivações do presidente para lançar o projeto de união homoafetiva. Karina Barcenas Barajas e Gloria Careaga-Perez - estudiosas das relações de g54ênero e sexualidade ${ }^{11}$ - reafirmaram essa inexistência. Mas, segundo Careaga-Perez, o discurso que Peña Nieto fez na celebração do Dia Nacional de Luta Contra a Homofobia, em 17 de maio de 2016, serviu de base para que a maioria dos órgãos governamentais federais iniciassem ações em favor dos direitos da população LGBTQIA+. Ainda, segundo essa estudiosa, os direitos dessa população, na gestão de Peña Nieto, foram reconhecidos pela totalidade dos órgãos/secretarias do seu governo.

Na Convocatória da Assembleia Nacional Ordinária do PRI ${ }^{12}$, em maio de 2013, foi elaborada a Declaração de Princípios intitulada "Un México Compartido" como resultado dos Trabalhos da Comissão Nacional de Deliberação de Documentos Básicos. Este documento trouxe, para o início do governo de Peña Nieto, questões relativas à equidade de gênero, além da especificidade das diversidades. Exigia aplicação de regras e políticas públicas que impedissem diferenças como as de raça, gênero, preferência sexual, entre outros grupos vulneráveis, e aplicação de regras para qualquer forma de

11 Por meio de entrevistas via e-mail, com Careaga-Perez, em 11 de julho de 2018, e Barcenas Barajas, em 12 de julho de 2018 .

${ }^{12}$ As assembleias constituem-se num órgão decisor desse partido e ocorrem a cada três anos. Nelas são discutidos e definidos o perfil e os rumos do partido, reformulados documentos básicos, debates são realizados sobre a situação política e eleitoral do partido para definir políticas e linhas de ação, assim como o projeto de nação do partido. 
discriminação. Pronunciava-se por uma sociedade voltada à igualdade de gênero e ao estabelecimento de uma cultura de respeito e inclusão entre homens e mulheres (DECLARAÇÃO DE PRINCÍPIOS DA XXII ASSEMBLEIA NACIONAL DO PRI, 2013). Na mesma linha, o Programa de Ação elaborado na Assembleia salientava a necessidade de ações relativas à condição e igualdade de gênero, educação sexual e defesa do direito a diferença (PROGRAMA DE ACCIÓN DO PRI, 2013).

Posteriormente, na Declaração de Princípios da XXII Assembleia Nacional do PRI, ocorrida em agosto de 2017, o partido deu ênfase ao compromisso e à promoção dos Direitos Humanos, com o objetivo de potencializar a cidadania no México (DECLARAÇÃO DE PRINCÍPIOS DA XXII ASSEMBLEIA NACIONAL DO PRI, 2017, p. $7 ; 11)^{13}$. Neste documento, além de ser utilizada a linguagem inclusiva, assinalando separadamente homens e mulheres (cidadãos/cidadãs, mexicanos/mexicanas), dos quarenta e dois itens destacados no documento, dez afirmaram compromissos para promover ações afirmativas e políticas públicas de enfrentamento dos problemas cotidianos e culturais vivenciados pelas mulheres, como a violência, a desigualdade, falta de oportunidades, entre outros. Destes, somente um destacou o reconhecimento da diversidade sexual, no conjunto com as outras existências discriminadas - raça, gênero, idade, cultura, religião, deficiência etc.

O Programa de Ação, também resultante dessa assembleia, frisou, em seus objetivos e linhas de ação, a equidade de gênero, numa tentativa de diminuir a distância entre homens e mulheres, assim como dizimar a violência sofrida por elas. Foram seis itens designados a essa questão, além do eixo transversal "Igualdad sustantiva", no qual explicitaram que a igualdade se constituía em uma das pendências mais significativas da sociedade mexicana. A diversidade sexual foi abordada no item que tratou da inclusão

\footnotetext{
${ }^{13}$ Os tópicos da Declaração de Princípios da XXII Assembleia Nacional do PRI são: Antecedentes; Orientação ideológica do partido; Liberdade; Direitos Humanos. Dois aspectos explicitados no documento são importantes de serem destacados aqui, quais sejam, a reafirmação das raízes do partido ancoradas na República Liberal, laica e federalista e a autonomia do partido, declarando que não são aceitos apoios econômico, político ou de propaganda de várias entidades, inclusive de organizações religiosas e de igrejas.
} 
da população vulnerável - item nove do Programa (PROGRAMA DE ACCIÓN DO PRI, 2017).

As questões acima apresentadas nos levam a refletir sobre a utilização do conceito de gênero, numa perspectiva primária e simplista, ainda muito comum. Joan Scott, em seu artigo "Gênero: uma categoria útil de análise histórica?", revela que duas formas de abordagem são utilizadas no uso da categoria gênero - uma de ordem mais descritiva, destituída de interpretação, e outra causal, que elabora teorias sobre a natureza dos fenômenos e das realidades. No seu uso mais simples, gênero tornou-se sinônimo de mulheres, podendo ser encontradas produções acadêmicas que substituíram o termo "mulheres" pelo de "gênero", com o intuito de indicar a seriedade, objetividade e neutralidade da pesquisa/análise (SCOTT, 1995, p. 71-99).

Por outro lado, na atualidade, os estudos de gênero não se restringem às discussões pertinentes a mulheres e homens, masculino e feminino. De acordo com Adriana Piscitelli, as normas de gênero "[...] ampliam a ideia de humano, abrindo o espaço da compreensão, da inteligibilidade e da dignidade também para todos/as os/as “diferentes” em termos de gênero e sexualidade" (PISCITELLI, 2009, p. 146).

Considerando a forma como esse conceito aparece nos documentos analisados, pode-se constatar que a utilização da noção de gênero refere-se a demanda das mulheres mexicanas, transformando essa expressão numa categoria social ou política específica o que não inclui indivíduos com outras formas de vivência da sexualidade, que não a heterossexual. Nesse sentido, as políticas e ações voltadas aos indivíduos LGBTQIA+ não são englobadas pela designação "gênero". Percebe-se, inclusive, que a expressão recorrente utilizada nos documentos é "equidade de gênero" 14 , deixando bastante claro que se trata da desigualdade entre homens e mulheres. Em todos os documentos oficiais do PRI analisados (programas de governo, declaração de princípios, programas de ação, plano de desenvolvimento e a Constituição Política do México - reformas de 2011 e 2014), a homossexualidade e outras vivências vêm denominadas como "preferência

\footnotetext{
14 "Equidade de gênero" é a designação encontrada em todos os documentos políticos do México e significa igualdade entre homens e mulheres.
} 
sexual" e vinculadas à chave dos Direitos Humanos, sob o aspecto da não discriminação. As políticas ou pautas voltadas à "equidade de gênero" são específicas da condição social da mulher e suas especificidades, como gravidez, trabalho, viuvez, saúde, segurança social, violência, entre outros. Não há associação da perspectiva de gênero àqueles e àquelas que vivem de forma diferente a sua sexualidade ${ }^{15}$.

${ }^{15}$ Constata-se a mesma característica e forma de compreensão da questão do gênero nos programas dos
candidatos que concorreram à presidência da república para o sexênio 2018-2024. No plano apresentado
por Antonio Manuel Lopez Obrador, do partido MORENA, intitulado "Por qué luchamos", explicitando o
ponto 9 do seu programa "Por el respeto a los Derechos Humanos y contra la violencia", esclarece que o
partido é contra a violência homofóbica, de gênero e étnica, claramente distinguindo o público alvo da
violência (Disponível em: <https://morena.si/wp-content/uploads/2014/12/Programa-Morena.pdf $>$.
Acesso em: 26 fev. 2018.). Em entrevista cedida ao Jornal El País, Lopez Obrador anunciou que seu
governo apostará na equidade de gênero, com uma equipe que seria formada por 8 homens e 8 mulheres,
inclusive sendo a Secretaria de Governo e a Secretaria de Segurança do país dirigidas, pela primeira vez,
por mulheres. El País. López Obrador anuncia un Gobierno con equidad de género si logra la
presidência.
Disponível em: $<$ https://elpais.com/internacional/2017/12/14/mexico/1513281226 384544.html> . Acesso em: 02 ago. 2018. Na plataforma eleitoral de Ricardo Anaya, da coalizão PAN/PRD, denominada "Coalición Por México al Frente", perceberam-se assegurados a igualdade de gênero, da perspectiva dos Direitos Humanos, e o combate à violência, entre elas o feminicídio (destacando a diferença deste delito cometido especificamente contra as mulheres em relação ao homicídio). Disponível em: $<$ https://repositoriodocumental.ine.mx/xmlui/bitstream/handle/123456789/94343/CG2ex201712-22-rp-5. 1-a2.pdf>. Acesso em: 26 fev. 2018. 
Gênero: a prioridade em desenvolver políticas públicas voltadas às mulheres

Uma pesquisa atenta na internet ${ }^{16}$ permite perceber que o México, desde o início do século XXI, passou a problematizar as condições culturais e sociais de existência das mexicanas e investir em programas institucionais e políticas públicas voltadas às mulheres, em especial no tocante à desigualdade e violência ${ }^{17}$. Presente na Constituição Federal, "equidade de gênero" tem sido uma constante em documentos institucionais, programas e plataformas de governos, nos debates das convenções dos partidos etc. Pode-se inferir que se transformou, inclusive, em categoria política, como aponta Rogério Junqueira (2016), considerando tratar-se de ponto sempre presente e importante em discursos e promessas de presidenciáveis e de outros concorrentes a cargos políticos. Desigualdade de gênero, feminicídio ${ }^{18}$, racismo (principalmente

\footnotetext{
${ }^{16} \mathrm{O}$ corpus documental que deu suporte às análises presentes neste artigo pertence à rede multimídia. Foram sites institucionais de diversas vertentes ideológicas da imprensa mexicana e o site do governo mexicano - no qual encontram-se disponíveis, para consulta, programas, projetos e outras iniciativas relativas à "equidade de gênero".

${ }^{17}$ De 2012 a 2017, o Observatorio Ciudadano Nacional del Feminicidio (OCNF) registrou 12.796 assassinatos de mulheres, dos quais apenas $22 \%$ tiveram as investigações iniciadas como feminicídio. Disponível

em: $<\underline{\text { https://consorciooaxaca.org/2018/11/pronunciamiento-deja-epn-el-peor-contexto-de-violencia-contra-las }}$ -mujeres-en-mexico/>. Acesso em: 28/nov. 2021.

${ }^{18}$ Em 1992, o termo feminicídio foi cunhado pela pesquisadora feminista sul-africana Diana Russell, embora naquele momento não tenha se popularizado tanto. Em 1993, o México vivenciou casos de violência em série contra mulheres na Ciudad Juárez, e a antropóloga da Universidade Nacional Autónoma do México (UNAM), Marcela Lagarde y de Los Ríos, em decorrência dessa onda de assassinatos especificamente de mulheres, usou pela primeira vez na América Latina o termo "feminicídio" para descrever esses assassinatos. "Lagarde estudou a série de mortes na cidade como um fenômeno social e identificou semelhanças entre os casos: eles começavam com um cativeiro prolongado, em que a vítima sofria sadismo sexual, mutilação e morria por asfixia. Em seguida, seus corpos eram abandonados em espaços públicos. Para a pesquisadora, a importância de chamar os casos de feminicídio era evidenciar que não se tratava somente de um homicídio simples, mas de crimes de ódio extremo e específico contra mulheres". Disponível em: <https:/www.bbc.com/portuguese/internacional-38183545>. Acesso em: 23 jun. 2018. Muito tempo depois, em 14 de junho de 2012, o crime de Feminicídio foi incorporado no Código Penal Federal. Disponível em: $<$ http://www.diputados.gob.mx/LeyesBiblio/ref/cpf/CPF ref112 14jun12.pdf $>$. Acesso em: 23 jun. 2018.
} 
vivenciado pelas mulheres indígenas), entre outros, são exemplos da variedade de formas de violência que afetam as mulheres mexicanas.

Órgãos, instituições e documentos políticos analisados, independentemente do ano ou partido, trazem em suas referências e princípios, especificamente, a situação de vulnerabilidade e desigualdade da mulher na sociedade mexicana. Gênero é tratado como igualdade entre homens e mulheres, fim das diferenças no tocante aos aspectos sociais, econômicos, de oportunidades, entre outros. Está expressa em planos e programas de governos a prioridade em desenvolver políticas públicas voltadas às mulheres. Frente à grande disparidade entre homens e mulheres, no México, percebe-se que os partidos têm instituído a equidade de gênero como pauta e fundamento em suas propostas políticas. Gênero, portanto, passou a significar todas as questões que definem a situação da mulher nesta sociedade.

Mas antes deste novo século, este país, signatário da Organização das Nações Unidas (ONU), já recepcionava instituições comprometidas com a questão da desigualdade, submissão e violência contra as mulheres. Foi realizada na Cidade do México, em 1975, a Primeira Conferência Mundial sobre a Situação da Mulher, organizada pela ONU, cujo objetivo principal era o de atrair a atenção internacional para as necessidades das mulheres, investi-las de poder e fazer avançar a situação feminina ${ }^{19}$. A conferência foi considerada um marco no tocante à luta pelas mulheres $\mathrm{e}$ igualdade de gênero. No período da conferência, esta organização designou o ano de 1975 como o "Ano Internacional das Mulheres" e a "Década da Mulher (1976-1985)"20. De acordo com publicação encontrada na página do Geledés, essa conferência “"[...] teve

\footnotetext{
19 A primeira Conferência da Mulher aconteceu em 1975, na Cidade do México, e foi reivindicada a elaboração de um "guia de ação para acabar com a discriminação da mulher e favorecer o seu avanço social". A segunda foi em Copenhague (Dinamarca), em 1980 e, a que antecedeu a de Pequim, aconteceu em Nairóbi, no Quênia, em 1985 (MISKOLCI, 2017, p. 727).

20 Disponível em: $<$ https://minionupucmg.wordpress.com/2017/08/02/i-conferencia-mundial-sobre-a-situacao-da-mulher/>. Acesso em: 23 ago. 2018.
} 
como resultado a elaboração da Convenção sobre a Eliminação de todas as Formas de Discriminação contra as mulheres"21.

Em 2001, como fruto de promessa de campanha do presidente Vicente Fox relativa à prevenção e eliminação de todas as formas de violência, surgiu o Instituto Nacional de las Mujeres (INMUJERES) - atuante até o presente. Publicado no Diário Oficial em 2003, trata-se de órgão político com a finalidade de reger sobre a violência de gênero, organismo este ligado aos poderes executivo, legislativo e judiciário, no México. Constituiu-se numa entidade cujo compromisso é o de promover condições para a não discriminação, igualdade entre os gêneros, exercício de todos os direitos das mulheres e participação igualitária na vida política, cultural, econômica e social do país 22.

Em fevereiro de 2007, na presidência de Felipe Calderón, foi publicada a Ley General de Acceso de las Mujeres a una Vida Libre de Violencia, com a finalidade de prevenir e erradicar a violência contra as mulheres ${ }^{23}$. Desde sua publicação até a

\footnotetext{
${ }^{21}$ Esta Convenção foi aprovada pela Assembleia Geral das Nações Unidas por meio da Resolução 34/180, em 18 de dezembro de $1979 . \quad$ Disponível em: $<$ https://www.geledes.org.br/violencia-domestica-e-familiar-contra-mulher-lei-maria-da-penha-uma-anali se-juridica/>. Acesso em: 23 ago. 2018.

${ }^{22}$ Disponível em: <https://www.facebook.com/pg/InmujeresOf/about/?ref=page internal>. Acesso em: 23 ago. 2018.

${ }^{23}$ Em 2008, por ocasião da comemoração do Dia Internacional da Mulher, Felipe Calderón também já havia proposto o Programa Nacional para la Igualdad entre Mujeres y Hombres 2007-2012 (Prolgualdad), sob o discurso de eliminar a discriminação e promover a igualdade entre homens e mulheres. Disponível em: $<$ http://www.jornada.com.mx/2008/03/07/index.php?section=sociedad\&article=047n1soc $>$. Acesso em: 23 ago. 2018. Para acessar o documento, procurar: $<$ http://imumi.org/attachments/INMUJERES-Politica Igualdad 2010.pdf>. Acesso em 23 ago. 2018. No entanto, em uma reportagem do periódico Contralínea, de 2011, duras críticas foram feitas a Felipe Calderón por ter diminuído o valor das verbas direcionadas aos programas de equidade de gênero. Nesta mesma matéria, a coordenadora da Red por los Derechos Sexuales y Reproductivos en México (Ddeser) lembra que no período do governo do PAN várias leis inovadoras foram aprovadas, tais como a Ley General de Acceso de las Mujeres a una Vida Libre de Violencia; los programas para reducir la mortalidad materna, y la Norma Oficial Mexicana (NOM), Violencia Familiar, Sexual y contra las Mujeres. Mas, segundo ela, acabaram ficando apenas no papel. Destaca, exemplificando, que os direitos sexuais e reprodutivos sofreram grandes retrocessos. O periódico, ainda, referendando a reportagem com imagens, mostra mulheres nas ruas protestando e denunciando a ineficiência dos programas do governo para combater $\quad 0$ feminicídio. $<$ https:/www.contralinea.com.mx/archivo-revista/2011/03/06/con-calderon-cae-gasto-federal-de-equidadde-genero/>. Acesso em 23 ago. 2018.
} 
atualidade (pois ainda está em vigor), vem sofrendo reformulações, de acordo com as transformações e demandas da sociedade e da necessidade do país - como as alterações de janeiro de 2011 e dezembro de 2015. Essa lei está baseada em quatro princípios, quais sejam, igualdade legal entre mulheres e homens; respeito pela dignidade humana das mulheres, a não discriminação e a liberdade das mulheres. Trata-se de uma lei que define os tipos de violência vivenciados pelas mulheres (psicológica, física, econômica, patrimonial e sexual), evidenciando que a violência produz muito mais que traumas físicos. Define os âmbitos e a modalidade em que elas sofrem essas formas de agressão, como a violência familiar, trabalho e ensino, violência comunitária e violência institucional $^{24}$. Nesta lei encontra-se estabelecido um mecanismo de proteção aos direitos humanos das mulheres denominado de Alerta de violencia de género contra las mujeres $(A V G M)$. Trata-se de um conjunto de ações do governo para erradicar a violência ou a possibilidade desta em um determinado espaço, município, dentro do país, praticada por indivíduos ou pela própria comunidade. De acordo com o artigo 23, tem como objetivo "Garantizar la seguridad de mujeres y niñas, el cese de la violencia en su contra y/o eliminar las desigualdades producidas por una legislación o política pública que agravia sus derechos humanos." 25 .

O governo de Enrique Peña Nieto também se empenhou em instituir programas e planos para combater a violência contra as mulheres ${ }^{26}$. Por meio do Centro Nacional de Equidad de Género y Salud Reproductiva, centro este que se constitui em uma unidade da Subsecretaría de Prevención y Promoción de la Salud, publicou, em

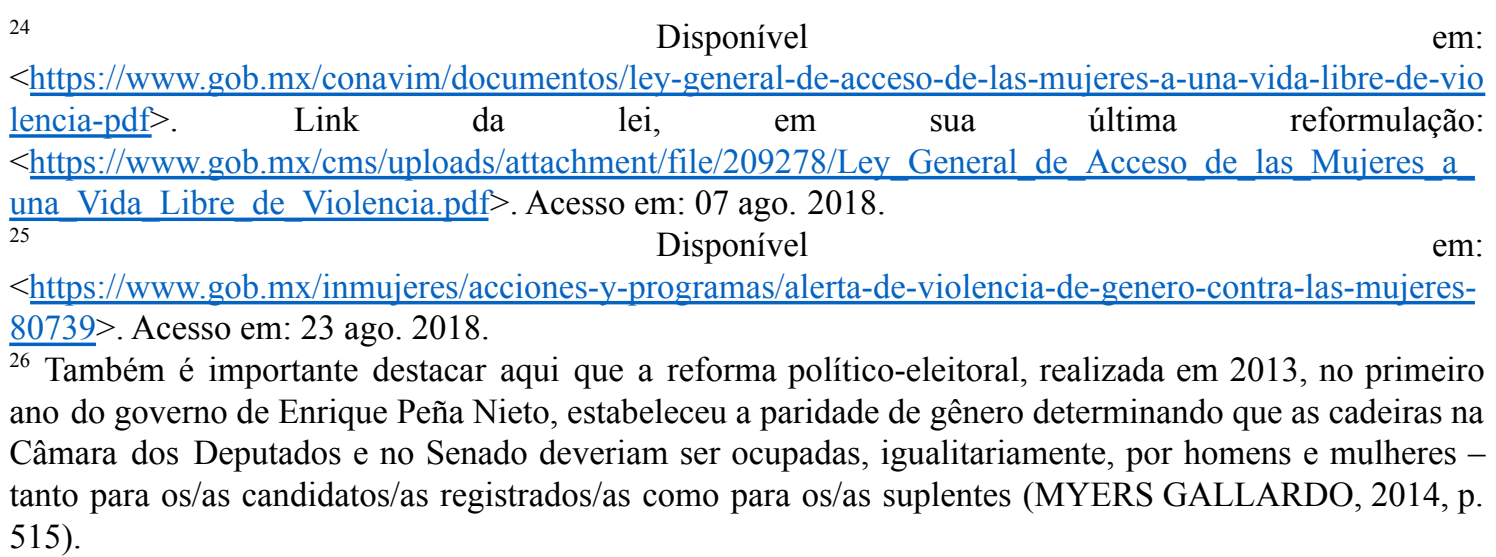


2014, diversos Programas Específicos de Ação voltados à saúde da mulher. Esses programas compuseram as estratégias delineadas para alcançar a meta de um México Incluyente, proposta no Plano de Ação do Governo para operacionalizar políticas públicas com o objetivo de proteger a saúde de jovens e adolescentes, mulheres e mulheres grávidas. Tratou-se de seis programas, especificamente: igualdad de género en salud; prevención y atención de la violencia; prevención y control del cáncer de la mujer; planificación familiar y anticoncepción; salud materna y perinatal e salud sexual y reproductiva para adolescentes ${ }^{27}$. Derivado do Plano Nacional de Desenvolvimento, institucionalizou também o PROIGUALDAD - Programa Nacional para la Igualdad de Oportunidades y no Discriminación contra las Mujeres -, para o período de sua gestão $(2013-2018)^{28}$. O objetivo proposto foi o de incorporar, de forma transversal, a igualdade de gênero nas políticas públicas, programas e projetos, como ações afirmativas concebidas e implementadas pela administração pública federal ${ }^{29}$.

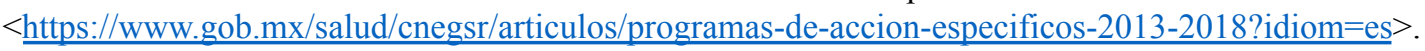
Acesso em: 21 ago. 2018.

${ }^{28} \mathrm{Na}$ atualidade, mesmo depois das eleições que confirmaram Andrés Manuel López Obrador, do MORENA (partido opositor ao PRI de Enrique Peña Nieto), à presidência da República, outras ações continuaram demonstrando a preocupação deste governo com o assunto. Uma plataforma digital para prevenir a violência contra as mulheres foi desenvolvida pela Subsecretaría de Prevención y Participación Ciudadana juntamente ao Banco Interamericano de Desarrollo (BID) com a contribuição, em forma de fóruns, de algumas universidades (Universidad Nacional Autónoma de México; Universidad Autónoma Metropolitana e Colegio de México). Tal instrumento pode ser encontrado em: $<$ https://www.gob.mx/segob/prensa/gobierno-y-academia-trabajan-para-erradicar-brecha-de-desigualdadde-genero?idiom=es $>$. Acesso em: 20 ago. 2018.

${ }^{29}$ Disponível em: <http://estadistica.inmujeres.gob.mx/formas/pyc.php?IDPrograma=1>. Acesso em: 23 ago. 2018. 


\section{Conapred: direitos humanos, a não-discriminação e a diversidade} sexual

A igualdade e a não-discriminação estão entre os princípios essenciais dos Direitos Humanos e da Democracia, presentes em normas internacionais, como nas da Organização das Nações Unidas - ONU -, criada em 1945, na Organização dos Estados Americanos - OEA - de 1948 e na Carta Democrática Interamericana, assinada em $2001^{30}$. As normativas e instrumentos contra a discriminação foram tomando corpo e tornando-se cada vez mais presentes em atos e legislações, independentemente da existência de instrumentos antidiscriminatórios regulamentados pelas nações - em especial na América -, conforme nos demonstra Nathália Vince Esgalha Fernandes (2016, p. 57-61). Os países que compunham a ONU passaram a estabelecer leis e criar instituições para combater a discriminação e desigualdade ${ }^{31}$.

O México, em 2003, criou o Consejo Federal Prevenir y Eliminar la Discriminación - CONAPRED - em favor da luta antidiscriminatória, no contexto dos Direitos Humanos. De acordo com Alejandro Becerro Gelover, esse tema só se tornou público no México nas eleições do ano 2000, quando os candidatos trouxeram essa questão para o debate político (BECERRA GELOVER, 2008. p. 61). Nesse ano, o PRI perdeu a sua primazia com o êxito de Vicent Fox, candidato do PAN e em março de 2001, foi instalada a Comisión Ciudadana de Estudios contra la Discriminación. Foram realizados 7 foros regionais, entre eles o da discriminación contra las mujeres en

\footnotetext{
30 A Carta Democrática Interamericana constitui-se em um instrumento da OEA (Organização dos Estados Americanos), assinada em 2001. Trata-se de um compromisso acordado por vários países no sentido de manter e fortalecer a democracia na América, principalmente motivados pelo fato de vários países estarem saindo de um período de ditadura e apresentarem "democracias frágeis" (definição presente na própria Carta). Carta Democrática Interamericana. Disponível em: $<$ http://www.oas.org/pt/democratic-charter/pdf/demcharter pt.pdf>. Acesso em: 10 ago. 2018.

31 Como referência tem-se: Comissão pela Igualdade Racial (1976), na Inglaterra; Centro de Igualdade de Oportunidades e de Luta contra o Racismo (1993), na Bélgica; HALDE - instituição criada para combater a discriminação - atualmente podendo ser encontrada sob a denominação Défenseur des droits , (2001), na França. Na América Latina, países como Brasil, Costa Rica, Colômbia, Equador, Guatemala, Panamá, Peru, Argentina, Uruguai e México normatizaram a proibição por meio de leis, ou criação de regras, e/ou alteração de parte das Constituições (FERNANDES, 2016, p. 62-65).
} 
Ciudad Juárez e o da Discriminación por preferencia sexual y temas de desarrollo humano y pobreza, em Guadalajara. Em novembro, foram concluídos os trabalhos da comissão, apresentados os resultados para os poderes Executivo e Legislativo, assim como para a opinião pública, e um ante projeto de lei para prevenir e eliminar a discriminação - que se converteu em lei no dia 12 de junho de 2003, a Ley Federal para Prevenir y Eliminar la Discriminación (LFPED) (BECERRA GELOVER, 2008. p. 62-64) $)^{32}$. O Congresso deliberou por adicionar um terceiro parágrafo no artigo primeiro da Constituição mexicana, voltado à não discriminação, assim elaborado:

Queda prohibida toda discriminación motivada por origen étnico o nacional, el género, la edad, las capacidades diferentes, la condición social, las condiciones de salud, la religión, las opiniones, las preferencias, el estado civil o cualquier otra que atente contra la dignidad humana y tenga por objeto anular o menoscabar los derechos y libertades de las personas ((BECERRA GELOVER, 2008. p. 64).

Em decorrência de todos os estudos feitos - que culminaram com o parágrafo no artigo $1^{\circ}$ da Constituição e a Lei Federal, em abril de 2004 - foi instalado formalmente um órgão do Estado para dirigir a luta institucional pela prevenção e erradicação da discriminação, o CONAPRED - Consejo Nacional para Prevenir la Discriminación, um “organismo público semiautónomo cuya meta es justamente combatir la discriminación a nivel institucional y promover condiciones de igualdad para todas las personas" (BECERRA GELOVER, 2008. p. 65).

A lei maior deste país também foi reformulada a partir da perspectiva dos Direitos Humanos, imprimindo e formalizando a luta pela não discriminação. A Constituição Política dos Estados Mexicanos, como lê-se no texto atualizado em 2014,

\footnotetext{
${ }^{32}$ Becerra Gelover (2008, p. 63) ainda explica que "La Comisión se propuso dos objetivos prácticos básicos. Por un lado, se buscaba que con los insumos generados como resultado de las discusiones pudiera elaborarse un proyecto legal que fuera propuesto a los poderes Ejecutivo y Legislativo, mismo que considerara tanto protecciones efectivas para toda persona contra cualquier acto de discriminación como la aplicación de políticas de compensación y de promoción que el Estado debería garantizar a quienes integran los grupos tradicionalmente expuestos a la discriminación. La otra meta consistía en impulsar la conformación de um órgano de Estado con atribuciones para promover y vigilar el cumplimiento de la propia ley que se estaba impulsando con el fin de penalizar la discriminación, así como para conducir la política antidiscriminatoria en México".
} 
capítulo I, "De Los Derechos Humanos Y Sus Garantías", artigo 1", parágrafo 50, deixou explícita a proibição a várias formas e motivos de discriminação, inclusive em relação às "preferencias sexuales". A atualização desse artigo ocorreu em 2011, período em que foram feitas alterações na Constituição mexicana relativas aos Direitos Humanos. O texto que vigorava na versão anterior trazia somente a expressão "preferências", num sentido mais vago, e então foi acrescentada a palavra "sexuais", deixando mais claro a que tipo de discriminação aquele item se referia.

(...) Queda proibida toda discriminación motivada por origen étnico o nacional, el género, la edad, las discapacidades, la condición social, las condiciones de salud, la religión, las opiniones, las preferencias sexuales, el estado civil o cualquier outra que atente contra la dignidade humana y tenga por objeto anular o menoscabar os derechos y libertades de las personas (CONSTITUCIÓN POLÍTICA DE LOS ESTADOS UNIDOS MEXICANOS, 2014, p. 11). (grifos nossos)

Essa reforma, de acordo com Tonatiuh García Castillo, adequou a legislação mexicana às normas dos Direitos Internacionais reconhecidas nos tratados assinados pelo país, em matéria de Direitos Humanos, buscando oferecer proteção mais ampla a todos os indivíduos (GARCÍA CASTILLO, 2015, p. 645-696). O preceito da não discriminação foi introduzido como um princípio transversal, aplicado em relação a todos os direitos humanos e liberdades, proibindo a discriminação relativa a várias categorias, como sexo, raça e cor, complementando, ainda, com o princípio da igualdade (GARCÍA CASTILLO, 2015, p. 666). Percebe-se, desta forma, que a partir dessa reforma, os programas de governo, as declarações de princípios, plataformas eleitorais, programas de ação, entre outros, passaram a ter os Direitos Humanos como referência.

A tônica na observação e efetivação dos Direitos Humanos na presidência de Enrique Peña Nieto é bastante perceptível. Neste governo foi criado, em abril de 2014, o Programa Nacional de Direitos Humanos, com a função de efetivar a implementação da reforma constitucional de $2011^{33}$. Para o quadriênio de 2014-2018, sob a direção da Unidade para a Defesa dos Direitos Humanos (pertencente à Subsecretaria de Direitos

\footnotetext{
${ }^{33}$ Disponível:<http://www.gobernacion.gob.mx/es mx/SEGOB/Programa Nacional de Derechos Huma

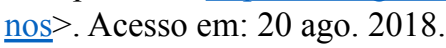


Humanos), foram produzidos vários materiais para o selo "Mis Derechos", entre eles um intitulado "Tengo derecho a vivir mi orientación sexual e identidad de género" ${ }^{\text {"34 }}$. De acordo com o que se encontra expresso na página virtual da Secretaria de Gobernación, esses instrumentos possuiriam a finalidade de consolidar a política em relação à problemática dos Direitos Humanos, no sentido de informar, dar a conhecer, divulgar e compartilhar nas redes sociais a variedade desta temática.

Embora não apareça explicitamente no Plano de Desenvolvimento de seu governo, Peña Nieto se empenha em encampar a luta do movimento LGBTQIA+. Em 17 de maio de 2016, dia da Luta contra a Homofobia, no México, a Secretaría de Gobernación publica em sua plataforma digital Gob.mx, sob o título ¿Qué es la identidad de género?, um texto explicativo sobre a diversidade sexual. Junto a essa publicação foi disponibilizado para acesso um vídeo produzido pelo Conselho dos Direitos Humanos da ONU intitulado "Libre e Iguales: Por qué luchamos", cujo objetivo seria o de divulgar e conscientizar a respeito da "luta para acabar com a violência e a discriminação" - palavras expressas na própria mensagem audiovisual ${ }^{35}$.

Nesse mesmo dia, o presidente Enrique Peña Nieto participa da celebração do Día Nacional de la Lucha Contra la Homofobia, realizada na Residencia Oficial de Los Pinos, e em seu pronunciamento anuncia o envio de uma iniciativa de reforma do Código Civil Federal com a finalidade de assegurar o matrimônio igualitário no país. Coloca-se disposto a um diálogo aberto no sentido de entender, escutar e propor políticas e ações para combater a discriminação e o respeito aos indivíduos LGBTQIA+.

\footnotetext{
34 Este documento está disponível em: $<$ https://www.gob.mx/cms/uploads/attachment/file/92220/013 Orien Sexual.pdf>. Outros documentos produzidos e disponíveis para serem divulgados: Mis Derechos: Soy niña, soy niño, soy adolescente; Mis Derechos: Soy mujer; Mis Derechos: Soy una persona con discapacidad; Mis Derechos: Soy una persona adulta mayor; Mis Derechos: Soy una persona migrante; Mis Derechos: Soy una persona indigena; Mis Derechos: Soy una persona afromexicana; Mis Derechos: Tengo derecho a un ambiente sano; Mis Derechos: Tengo derecho a la salud, e tantos mais. Podem ser encontrados em $<$ https://www.gob.mx/segob/documentos/misderechos-por-una-cultura-de-los-derechos-humanos-31435?i diom=es > . Acesso em: 18 ago. 2018.

${ }_{35}$ Disponível em: <https://www.gob.mx/segob/articulos/que-es-la-identidad-de-genero>. Acesso em: 07 ago. 2018.
} 
Sobre a diversidade sexual, afirma, em seu discurso, o reconhecimento e compromisso com essa população:

\begin{abstract}
Reitero mi más amplio reconocimiento a su compromiso, quiero decirles a todos ustedes, con los derechos humanos y la no discriminación por motivos de orientación o preferencia sexual, o de identidad de género. Ratifico el compromiso de mi Gobierno con la no discriminación y por la construcción de un México, verdaderamente incluyente, donde todas las personas puedan ejercer sus derechos a plenitud ${ }^{36}$.
\end{abstract}

Seguindo uma pauta inclusiva, instrui as diversas secretarias presentes (Gobernación, Salud, Educación Pública, Seguridad Social e o CONAPRED - Consejo Nacional para Prevenir La Discriminación) sobre a realização de ações para atender as propostas apresentadas pelos outros integrantes - estudiosos(as), políticos e ativistas que compunham a mesa, além da realização de campanhas nacionais contra a homofobia.

Por fim, assume quatro determinações, quais sejam: iniciativa para reforma do artigo $4^{\circ}$ da Constituição, para incorporar critérios explícitos para o reconhecimento do casamento igualitário; iniciativa para reforma do Código Civil Federal e indicação para que fosse replicado nos Códigos Civis de todos os Estados - e assinala, para o representante da Secretaría de Relaciones Exteriores, que fossem tomadas as medidas necessárias àqueles e àquelas que solicitassem passaportes - que fossem reconhecidos e aceitos, sem distinção, "las actas de nacimiento que registran un cambio sexogénico"; determina a revisão de documentos, nas três ordens do governo, que em suas letras, conteúdos e expressões não contenham teor discriminatório e que seja reconhecida a diversidade; e, por fim, na sua última determinação, indica que o México participe do

\footnotetext{
${ }^{36}$ Palavras de Enrique Peña Nieto, na celebração do Dia Nacional de Luta Contra a Homofobia, em maio de 2016.2 Disponível em: $<$ https://www.gob.mx/presidencia/prensa/palabras-presidente-de-los-estados-unidos-mexicanos-enrique-p ena-nieto-en-la-celebracion-del-dia-nacional-de-la-lucha-contra-la-homofobia >. Acesso em: 02 ago. 2018.
} 
núcleo de discussões e trabalho das Nações Unidas, relativo às pessoas LGBTQIA+, núcleo este cujo objetivo é o de promover os Direitos Humanos internacionalmente ${ }^{37}$.

Permeado por um discurso bastante liberal no tocante aos costumes e à moral conservadora, percebe-se que este pronunciamento e respectivas propostas de ações, não deixariam de significar também uma oportunidade para que o presidente mostrasse suas intenções sobre a inclusão dos indivíduos LGBTQIA+, ao mesmo tempo em que se promovia politicamente. Nesse período, a impopularidade de Peña Nieto era destaque na imprensa devido à economia estagnada e ao crescimento da violência. Sua forma de fazer política incorporando demandas sociais era considerada, por alguns, como populistas. Essa debilidade foi alvo e motivo para que a Igreja engrossasse o coro dos descontentes com a sua administração ${ }^{38}$. Suspeitas de corrupção, a tragédia de Iguala $^{39}$, violência devido ao narcotráfico, falta de segurança, atraso e desigualdade econômica, promessas que não foram cumpridas, levaram a uma crise nacional e a tentativa, por parte do governo, de recuperar a iniciativa política de reformar e colocar em prática a modernização do país.

Um outro aspecto a ser considerado diz respeito ao fato de que, ao assumir a presidência, Enrique Peña Nieto assinou um acordo, juntamente aos partidos PAN e PRD (Partido da Revolução Democrática), que impunha metas para impulsionar reformas políticas no país. O documento intitulado "Pacto pelo México" baseou-se em

\footnotetext{
${ }^{37}$ Pronunciamento do Presidente Enrique Peña Nieto na celebração do Día Nacional de la Lucha Contra la Homofobia, publicado no portal do governo. Disponível em: $<$ https://www.gob.mx/presidencia/prensa/palabras-presidente-de-los-estados-unidos-mexicanos-enrique-p ena-nieto-en-la-celebracion-del-dia-nacional-de-la-lucha-contra-la-homofobia>. Acesso em: 02 ago. 2018.

${ }^{38}$ Disponível em: < https://brasil.elpais.com/brasil/2016/09/24/internacional/1474675954 946407.htmll>. Acesso em: 27 nov. 2017.

${ }^{39}$ A tragédia de Iguala refere-se ao "desaparecimento e a morte, em 26 de setembro, de 43 humildes estudantes de magistério em Iguala, no Estado de Guerrero." Disponível em: $<$ https://brasil.elpais.com/brasil/2014/12/07/internacional/1417916004 502575.html $>$. Acesso em: 27 nov. 2017.
} 
três eixos: fortalecimento do Estado, modernização econômica e política, ampliação e aplicação de direitos sociais ${ }^{40}$.

Considerando os dois últimos itens, podemos presumir que o projeto de conjugalidade homoafetiva pode ter consistido em uma das ações voltadas à causa dos direitos sociais e cidadania, ao mesmo tempo em que o projetava, internacionalmente, como um governo observador das demandas das instituições às quais o México era signatário. Pressupõe-se tratar de investimento político estratégico, embora com temática polêmica, mas que redirecionava o foco das críticas, uma vez que se encontrava em meio a uma grande crise de popularidade

\section{Considerações finais}

A História das Mulheres teve como ponto de partida a política feminista. A origem desse campo de estudos, mostra-nos Joan Scott (1992, p. 64), situa-se na década de 1960, quando ativistas feministas reivindicavam o reconhecimento da atuação de mulheres na história, suas motivações e a opressão vivida por elas. Na década de 70, a História Social operou como veículo para a História das Mulheres, cujo novo conjunto de abordagens enfatizou a importância e legitimidade do estudo das mulheres. Nesse período também foram criadas outras percepções sociais sobre o que significava ser uma mulher, e a "categoria mulheres" assumiu uma existência como entidade social separada da "categoria homens". A História das Mulheres confirmou a realidade da categoria "mulheres" e deu-lhes uma história (SCOTT, 1992, p. 81-83). O desafio no final desta década foi o da viabilidade desta "categoria" e a introdução da "diferença" como problema a ser analisado.

Era necessário um modo de pensar sobre a diferença e como sua construção definiria as relações entre os indivíduos e os grupos sociais. [...] "Gênero" foi

\footnotetext{
40

$<$ https:/www.gazetadopovo.com.br/mundo/partidos-politicos-assinam-pacto-pelo-mexico-para-impulsion ar-reformas-1y3gm6cb08e44tz6z9k300qq6/ >. Acesso em: 28 nov. 2017.
} 
o termo usado para teorizar a questão da diferença sexual. [...] as feministas escolheram enfatizar as conotações sociais de gênero em contraste com as conotações físicas de sexo (SCOTT, 1992, p. 86).

Scott (1992, p. 87) ressalta que a categoria gênero foi utilizada, a princípio, para que se refletisse sobre as diferenças entre os sexos e, depois, sobre a produção das diferenças dentro das diferenças.

Em um outro artigo, Scott sublinha que a noção de gênero apresenta, em alguns estudos, uma perspectiva simplista e descritiva ao ser tomada como sinônimo de "mulher". O seu uso com tal conotação tinha o objetivo de indicar, como diz a autora, erudição e seriedade por apresentar-se mais objetivo e neutro do que o uso da categoria "mulher". Scott elucida essa questão: "Enquanto o termo "história das mulheres" revela sua posição política ao afirmar [...] que as mulheres são sujeitos históricos válidos, o "gênero" inclui as mulheres sem as nomear, e parece assim não se constituir em ameaça crítica" (SCOTT, 1995, p.71-99). No seu uso descritivo, reitera a autora, "gênero" figura como um conceito associado aos estudos das coisas referentes às mulheres.

Nos documentos oficiais, programas, projetos, ações, leis, e outros aqui analisados, pudemos perceber uma aproximação dos usos estabelecidos do conceito de gênero, mesmo tratando-se de dois espaços distintos, a política e a academia. Enquanto em algumas a noção de gênero passou a substituir a categoria mulher, a utilização do termo voltado às políticas públicas considerou somente sua aplicabilidade relativa à condição social e sexual das mulheres. As linhas de ação privilegiaram essa parcela da população mexicana, enquanto outros grupos sociais, minoritários, também problematizados por essa categoria analítica - LGBTQIA+ - ficaram ausentes das políticas públicas.

Os documentos mexicanos revelam essas formas de entendimento, substituindo o termo mulher por gênero ou utilizando-o para referenciar o aspecto relacional, ou seja, a diminuição da distância e diferenças entre os sexos - denominado como "equidade de gênero". Ao mesmo tempo em que enfatiza o caráter moderno e inclusivo do país, seguindo as normativas da ONU, ressaltando a importância de políticas voltadas a essa 
categoria, por outro lado desloca as práticas sexuais de seu significado. Dessa forma, programas e ações não só se apropriaram da forma mais simplista da compreensão do "gênero", mas, principalmente, seguiram a linha que poderia promover menos conflitos com grupos conservadores e "observadores" da moral e bons costumes cristãos, quais sejam, os defensores da família heterossexual.

Quanto ao projeto para aprovação da união entre pessoas do mesmo sexo, podemos inferir que se constituiu em estratégia política - em meio a uma grande crise de popularidade que Penã Nieto vivenciava. O casamento homossexual já havia sido outorgado pela Suprema Corte de Justiça em 2015, que considerava inconstitucionais as leis estaduais que proibissem o matrimônio igualitário ${ }^{41}$. Em 2009, a cidade do México foi a primeira a reconhecer a união homoparental e, em 2015, a Suprema Corte estabeleceu jurisprudência para legalizá-lo no país, determinando a sua proibição como inconstitucional. Em 2016, o Supremo Tribunal considerou legítimo um recurso promovido pela Comissão Nacional de Direitos Humanos, recurso este que solicitava à Suprema Corte de Justiça a invalidação o artigo do Código Civil de Puebla que mencionava "homem e mulher" ao definir o casamento, o que limitava outras configurações de união ${ }^{42}$.

Com o governo de Peña Nieto marcado pelo descontentamento da população e denúncias de corrupção, percebe-se uma tentativa política por meio da bandeira da modernização, cidadania e direitos sociais - neste caso das minorias - para tentar imprimir, em sua gestão, a marca de um governo liberal, democrático, inclusivo e respeitoso com a Constituição e afugentar a "nuvem pesada" da corrupção que pairava sobre sua gestão.

41

$<\underline{\text { https://www.terra.com.br/noticias/mundo/america-latina/apos-aval-para-casamento-homossexual-mexic }}$ o-realiza-parada-do-orgulho-gay,e6d7385c5a74da4babc16799fa5a126aupw3RCRD.html $>$. Acesso em: 02 set. 2018. https://www.informador.mx/Mexico/Suprema-Corte-avala-matrimonio-igualitario-en-Puebla-20170801-0 003.html. Acesso em: 02 set. 2017. 


\section{Referências bibliográficas}

\section{Fontes}

Carta Democrática Interamericana. Disponível em:

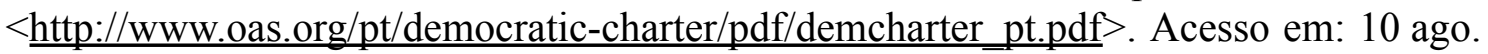
2018.

Constitución Política de los Estados Unidos Mexicanos, 2014. Disponível em:

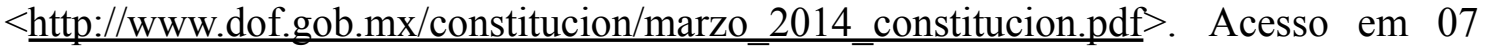
ago. 2018.

Declaração de Princípios da XXII Assembleia Nacional do PRI, 2017. Disponível em:

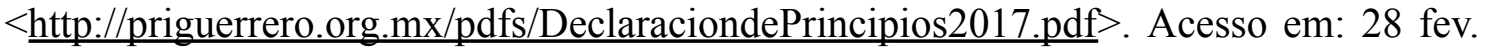
2018

Declaración de Principios de la XXI Asamblea Nacional Ordinaria del Partido Revolucionario Institucional - PRI. 2013. Disponível em: $<$ http://www.pridf.org.mx/NuestroPartido/Documentos.aspx $>$. Acesso em: 05 mar. 2018.

GOVERNO DO MÉXICO. Disponível em: $<$ https://www.gob.mx $>$. Acesso em: 07 ago. 2018 .

INMUJERES - $\quad$ Facebook. Disponível em: $<$ https://www.facebook.com/pg/InmujeresOf/about/?ref=page internal $>$. Acesso em: 23 ago. 2018.

INMUJERES.

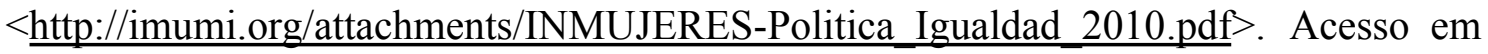
23 ago. 2018.

Plan Nacional de Desarrollo (2013-2018). Disponível em: <http://pnd.gob.mx/>. Acesso em: 28 fev. 2018.

Presidencia de la República. Disponível em: <https://www.gob.mx/presidencia/>. Acesso em: 20 nov. 2018.

Programa de Ação, PRI, $2017 . \quad$ Disponível em:

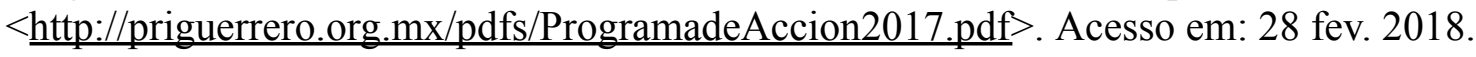




\section{Programa de Acción, PRI, 2013. Disponível em: $<$ http://www.pridf.org.mx/Documentos/ProgramadeAccion2013.pdf $>$. Acesso em: 07 mar. 2018.}

\section{Referências bibliográficas}

A tragédia de Iguala dem: $<$ https://brasil.elpais.com/brasil/2014/12/07/internacional/1417916004_502575.html $>$. Acesso em: 27 nov. 2017.

BECERRA GELOVER, Alejandro. Atención a la discriminación en Iberoamérica: un recuento inicial. México D.F.: CONAPRED, 2008. Disponível em:

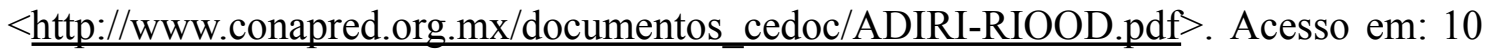
ago. 2018.

EL PAÍS. Igreja mexicana tira a ultradireita das catacumbas em ofensivas antigays. 24 set. $2016.2 \quad$ Disponível em:

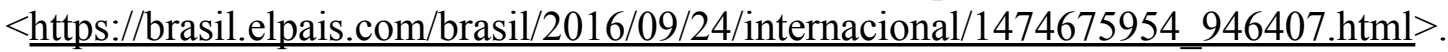
Acesso em 01 nov. 2018.

FERNANDES, Nathália Vince Esgalha. A luta institucional antidiscriminatória: Um estudo de caso do CONAPRED e da atenção à discriminação contra imigrantes centro-americanos no México. Dissertação (mestrado em Ciências Sociais) Universidade de Brasília, Brasília, 2016, p. 57-61. Disponível em: $<$ http://repositorio.unb.br/bitstream/10482/20846/1/2016 Nath\%C3\%A1liaVinceEsgalh aFernandes.pdf $>$. Acesso em: 05 mar.2018.

GARCÍA CASTILLO, Tonatiuh. La Reforma Constitucional Mexicana de 2011 en materia de Derechos Humanos. Una lectura desde el Derecho Internacional. In: Boletín Mexicano de Derecho Comparado. UNAM, Instituto de Investigaciones Jurídicas. Año XLVIII, no 143, mayo-agosto de 2015, pp. 645-696.

HAMNETT, Brian R. História concisa do México. Trad. Daniel Moreira Miranda. São Paulo: Edipro, 2016. pp. 157-255.

JUNQUEIRA, Rogério Diniz. "Ideologia de Gênero": uma categoria de mobilização política. In: SILVA, M. A. da (org.). Gênero e diversidade: debatendo identidades. São Paulo: Perse, 2016.

LOAEZA, Soledad. La restauración de la iglesia católica en la transición mexicana. México, D.F.: El Colegio de México, Centro de Estudios Internacionales, 2013. 
MISKOLCI, Richard, CAMPANA, Maximiliano. "Ideologia de gênero": notas para a genealogia de um pânico moral contemporâneo. In: Revista Sociedade e Estado. Vol. 32, no 3, Set/dez/2017. Pp. $725-747$.

MYERS GALLARDO, Alfonso. A reforma política no México: uma análise crítica dos avanços e retrocessos nas novas leis eleitorais do país. In: Revista Paraná Eleitoral. V.3, $\mathrm{n}^{\mathrm{o}} 3,2014$, pp. 491-520.

PÉREZ RAYÓN, Nora. El anticlericalismo en la historia de México, uma visión clerical: la acción anticatólica en México. México: Universidad Autónoma Metropolitana, Unidad Azcapotzalco, 2008.

PISCITELLI, Adriana. Gênero: história de um conceito. In: ALMEIDA, H. B; SZWAKO, J. E. (orgs.). Diferenças, igualdade. São Paulo: Berlendis \& Vertecchia, 2009.

SCOTT, Joan. Gênero: uma categoria útil de análise histórica? Educação e Realidade. Porto Alegre, v. 20, n. 2, p. 71-99, jul./dez. 1995.

SCOTT, Joan. História das Mulheres. In: BURKE, P. A escrita da História: novas perspectivas. São Paulo: Unesp, 1992.

\section{Sites pesquisados}

$<$ https://consorciooaxaca.org/2018/11/pronunciamiento-deja-epn-el-peor-contexto-de-vi olencia-contra-las-mujeres-en-mexico/> . Acesso em: 28 nov. 2021.

$<$ https://elpais.com/internacional/2017/12/14/mexico/1513281226_384544.html $>$. Acesso em: 02 ago. 2018.

$<\underline{\text { https://repositoriodocumental.ine.mx/xmlui/bitstream/handle/123456789/94343/CG2e }}$ x201712-22-rp-5.1-a2.pdf>. Acesso em: 26 fev. 2018.

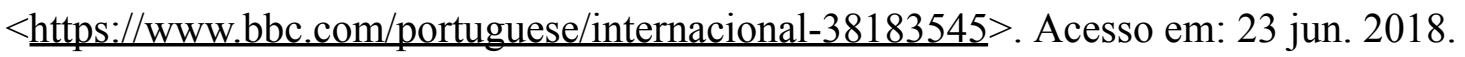

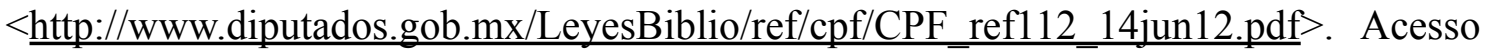
em: 23 jun. 2018.

$<$ https://minionupucmg.wordpress.com/2017/08/02/i-conferencia-mundial-sobre-a-situa cao-da-mulher/> . Acesso em: 23 ago. 2018.

$<\underline{\text { https://www.geledes.org.br/violencia-domestica-e-familiar-contra-mulher-lei-maria-da }}$ -penha-uma-analise-juridica/> . Acesso em: 23 ago. 2018. 
$<$ http://www.jornada.com.mx/2008/03/07/index.php?section $=$ sociedad\&article $=047 \mathrm{n} 1 \mathrm{~s}$ oc>. Acesso em: 23 ago. 2018.

$<$ https://www.contralinea.com.mx/archivo-revista/2011/03/06/con-calderon-cae-gasto-fe deral-de-equidad-de-genero/> . Acesso em 23 ago. 2018.

$<$ https://www.gob.mx/conavim/documentos/ley-general-de-acceso-de-las-mujeres-a-una -vida-libre-de-violencia-pdf>. Acesso em: 07 ago. 2018.

$<\underline{\text { https://www.gob.mx/inmujeres/acciones-y-programas/alerta-de-violencia-de-genero-co }}$ ntra-las-mujeres-80739 $>$. Acesso em: 23 ago. 2018.

$<$ https://www.gob.mx/salud/cnegsr/articulos/programas-de-accion-especificos-2013-201 $\underline{\text { ? idiom }=\text { es }}>$. Acesso em: 21 ago. 2018.

$<\underline{\text { https://www.gob.mx/segob/prensa/gobierno-y-academia-trabajan-para-erradicar-brech }}$ a-de-desigualdad-de-genero?idiom=es $>$. Acesso em: 20 ago. 2018.

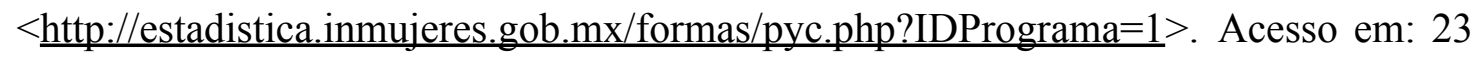
ago. 2018.

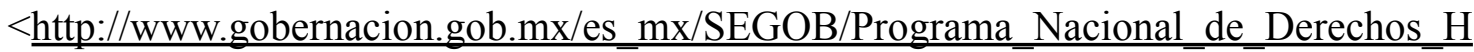
umanos >. Acesso em: 20 ago. 2018.

$<$ https://www.gob.mx/segob/documentos/misderechos-por-una-cultura-de-los-derechoshumanos-31435?idiom=es $>$. Acesso em: 18 ago. 2018.

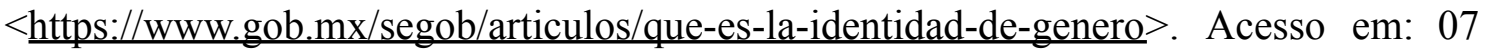
ago. 2018.

$<$ https://www.gob.mx/presidencia/prensa/palabras-presidente-de-los-estados-unidos-me xicanos-enrique-pena-nieto-en-la-celebracion-del-dia-nacional-de-la-lucha-contra-la-ho mofobia $>$. Acesso em: 02 ago. 2018

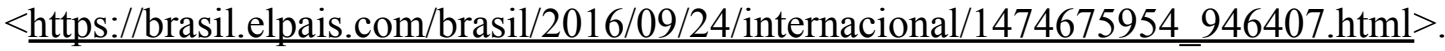
Acesso em: 27 nov. 2017.

$<$ https://www.gazetadopovo.com.br/mundo/partidos-politicos-assinam-pacto-pelo-mexi co-para-impulsionar-reformas-1y3gm6cb08e44tz6z9k300qq6/>. Acesso em: 28 nov. 2017. 
$<$ https://www.terra.com.br/noticias/mundo/america-latina/apos-aval-para-casamento-ho mossexual-mexico-realiza-parada-do-orgulho-gay,e6d7385c5a74da4babc16799fa5a 126 aupw3RCRD.html> . Acesso em: 02 set. 2018.

$<\underline{\text { https://www.informador.mx/Mexico/Suprema-Corte-avala-matrimonio-igualitario-en- }}$ Puebla-20170801-0003.html >. Acesso em: 02 set. 2017. 